\title{
Estimating the impact of a cancer diagnosis on life expectancy by socio-economic group for a range of cancer types in England
}

\author{
Elisavet Syriopoulou*, ${ }^{*}$, Hannah Bower ${ }^{2}$, Therese M-L Andersson ${ }^{2}$, Paul C Lambert ${ }^{1,2}$ and Mark J Rutherford ${ }^{1}$ \\ ${ }^{1}$ Biostatistics Research Group, Department of Health Sciences, University of Leicester, Centre for Medicine, University Road, \\ Leicester LE1 7RH, UK and ${ }^{2}$ Department of Medical Epidemiology and Biostatistics, Karolinska Institutet, SE-171 77, Stockholm, \\ Sweden
}

Background: Differences in cancer survival exist across socio-economic groups for many cancer types. Standard metrics fail to show the overall impact for patients and the population.

Methods: The available data consist of a population of $\sim 2.5$ million patients and include all patients recorded as being diagnosed with melanoma, prostate, bladder, breast, colon, rectum, lung, ovarian and stomach cancers in England between 1998 and 2013. We estimated the average loss in expectation of life per patient in years and the proportion of life lost for a range of cancer types, separately by deprivation group. In addition, estimates for the total number of years lost due to each cancer were also obtained.

Results: Lung and stomach cancers result in the highest overall loss for males and females in all deprivation groups in terms of both absolute life years lost and loss as a proportion of expected life remaining. Female lung cancer patients in the least- and most-deprived group lose 14.4 and 13.8 years on average, respectively, that is translated as $86.1 \%$ and $87.3 \%$ of their average expected life years remaining. Melanoma, prostate and breast cancers have the lowest overall loss. On the basis of the number of patients diagnosed in 2013, lung cancer results in the most life years lost in total followed by breast cancer. Melanoma and bladder cancer account for the lowest total life years lost.

Conclusions: There are wide differences in the impact of cancer on life expectancy across deprivation groups, and for most cancers the most affluent lose less years.

In many countries cancer survival varies by socio-economic status (Dalton et al, 2008; Van der Heyden et al, 2009; Sprague et al, 2011; Coleman, 2014; Ito et al, 2014). In the United Kingdom there have been national policies aimed at reducing inequalities (Department of Health, 2000; Department of Health, 2011), but any changes have been minor (Rachet et al, 2009; Rachet et al, 2010). Part of the observed differences in survival between socio-economic groups can be explained by stage at diagnosis (Rutherford et al, 2013; Morris et al, 2016).

Approaches to estimate the impact of cancer for a patient tend to rely on metrics that are relevant at a particular point in follow- up time after diagnosis, such as 1- or 5-year relative survival (Andersson et al, 2013). Relative survival is a measure that is not influenced by mortality due to other causes and is useful for comparing cancer survival between population groups or across time. However, it does not provide information on the life-time impact of a diagnosis of cancer.

An alternative measure that looks over the whole of the remaining life time is the loss in expectation of life resulting from a diagnosis of cancer (Andersson et al, 2015). Loss in expectation of life due to cancer is the difference between the life expectancy of those who are not diagnosed with cancer and the life expectancy 
of patients diagnosed with cancer (Andersson et al, 2013). It is possible to estimate a patient's loss in expectation of life based on the individual's characteristics such as age, sex and stage at diagnosis. To understand the impact of a cancer at a population level, the average and total loss in expectation of life for subgroups, for example, certain deprivation groups or stage groups, can be obtained. Compared to 5-year relative survival, loss in expectation of life is a more intuitive measure that can be easily interpreted and estimates the impact of the cancer for the whole lifespan of a person (Rutherford et al, 2015; Bower et al, 2016).

We assess the life-time impact of a diagnosis of cancer and how this varies by socio-economic status for a range of cancer types in England by estimating the loss in expectation of life and proportion of life lost.

\section{MATERIALS AND METHODS}

Data resources. Data were obtained on all individuals in England diagnosed with one of the cancer types of interest between the start of 1998 and the end of 2013 using National Cancer Registry Data provided by Public Health England. Cancer types with varying prognosis and characteristics such as age at diagnosis were carefully selected. The analysis included lung, stomach, ovarian, bladder, colon, rectum and breast cancers, melanoma and prostate cancer. International Classification of Diseases 10 was used to identify individuals with these cancers (see Table 1 for details). Information on the socio-economic status of the patients was available, and each of the patients was classified to one of five deprivation groups. The categorisation was based on national quintiles of the income domain of the index of multiple deprivation (IMD) 2010 score of the lower super output area of patients' residence at diagnosis (Neighbourhood Renewal Unit, 2004; Department for Communities and Local Government, 2011) and was available for the whole population of England. The overall IMD is a weighted area-level aggregation and not an individualspecific measure. For patients with multiple tumours only the first tumour for each cancer type was considered.

Statistical methods. We fitted flexible parametric relative survival models that use restricted cubic splines to capture the shape of the baseline excess hazard (Royston, 2001; Royston and Parmar, 2002; Nelson et al, 2007). Separate models were fitted for each cancer type and sex. From these models we predicted the loss in expectation of life and the proportion of life lost for each of the five deprivation groups using the approach by Andersson et al, 2013. Andersson et al showed that it is possible to consistently extrapolate cancer survival by extrapolating relative survival rather than observed survival. The main intuition of this approach is that as time since diagnosis increases the expected mortality rate dominates. Expected mortality rates were obtained from population mortality files stratified by sex, age, deprivation group and calendar year (Spika et al).

The models included deprivation group and age at diagnosis. Age was included in the models as a continuous variable but it was allowed to be non-linear through use of restricted cubic splines. The effect of deprivation and age at diagnosis were assumed to be time-dependent (i.e. relaxing the proportional excess hazards assumption). An interaction between age and deprivation was also included.

A period analysis with a period window between years 2007 and 2013 was conducted. The analysis included all individuals who

Table 1. Number of patients (mean age at diagnosis) for different cancer types by sex and deprivation group in England

\begin{tabular}{|c|c|c|c|c|c|c|}
\hline \multicolumn{7}{|c|}{ Deprivation quintile } \\
\hline \multicolumn{7}{|l|}{ Lung } \\
\hline Females & $27208(71.8)$ & $35866(71.9)$ & $42039(71.9)$ & $49477(71.6)$ & $57420(70.7)$ & $212010(71.5)$ \\
\hline \multicolumn{7}{|l|}{ Stomach } \\
\hline Males & 10741 (71.5) & $12954(72.0)$ & $13883(72.0)$ & $14737(71.8)$ & $15472(70.9)$ & $67787(71.6)$ \\
\hline \multicolumn{7}{|l|}{ Ovarian } \\
\hline Females & $17688(64.1)$ & $19466(64.5)$ & $19173(65.0)$ & $17540(64.1)$ & $14960(62.3)$ & $88827(64.0)$ \\
\hline \multicolumn{7}{|l|}{ Bladder } \\
\hline Males & $19171(73.1)$ & $21561(73.4)$ & $21714(73.3)$ & $20530(72.8)$ & $17845(71.7)$ & $100821(72.9)$ \\
\hline Females & $6621(75.0)$ & $7976(75.5)$ & $8214(75.6)$ & $8527(75.3)$ & $7683(74.3)$ & $39021(75.1)$ \\
\hline Males & $21125(68.6)$ & $22542(69.2)$ & $22411(69.4)$ & $20858(69.3)$ & $19029(68.6)$ & $105966(69.0)$ \\
\hline Females & $12995(70.1)$ & $14500(71.0)$ & $14403(71.5)$ & $13414(71.6)$ & $11484(70.7)$ & $66796(71.0)$ \\
\hline \multicolumn{7}{|l|}{ Breast } \\
\hline Females & $128807(61.5)$ & $131004(62.7)$ & $123949(63.3)$ & $109975(63.3)$ & $89758(62.5)$ & $583493(62.7)$ \\
\hline \multicolumn{7}{|l|}{ Melanoma } \\
\hline Males & $16822(61.8)$ & $15542(62.3)$ & $13257(62.1)$ & $9820(61.2)$ & $6156(59.8)$ & $61597(61.7)$ \\
\hline Females & $18299(58.2)$ & $17459(59.2)$ & $15097(59.3)$ & $11886(58.5)$ & $7533(56.6)$ & $70274(58.6)$ \\
\hline \multicolumn{7}{|l|}{ Prostate } \\
\hline Males & $113190(71.0)$ & $115485(71.6)$ & $103140(72.0)$ & $86737(72.0)$ & $69306(71.7)$ & $487858(71.6)$ \\
\hline
\end{tabular}


were under follow-up at any point from the beginning of the year 2007 until 31 December 2013, independent of whether they were diagnosed before or after year 2007. Period analysis has been widely shown to provide good predictions of the prognosis of newly diagnosed patients and highlights temporal trends in patient survival sooner than cohort methods (Brenner et al, 2002; Brenner and Hakulinen, 2007).

We calculated the averaged loss in expectation of life for each cancer type by a weighted average of the age-specific estimates. To do so we first estimate age-specific estimates within each deprivation, cancer type and sex group, and then obtain the weighted average. The weights reflect the age distribution of those diagnosed in year 2013, the most recent year in our study population for each deprivation group separately (internal standardisation). Loss in expectation of life is a highly agedependent measure because those at younger ages have more life years to lose initially. We therefore also estimated the proportion of life lost due to cancer. The proportion of life lost is defined as the loss in expectation of life for a person in our cancer population divided by the expectation of life for those who are not diagnosed with cancer but with similar characteristics.

We also estimated the total life years that would be lost due to cancer for a typical annual cohort size in England, using the cohort diagnosed in the year 2013 for each cancer type. This measure is calculated by multiplying the number of patients diagnosed with cancer by the average loss in expectation of life for each deprivation group.

All statistical analyses were conducted using Stata 14.1 (StataCorp., 2015).

See Supplementary Material for further details.

\section{RESULTS}

A population of $\sim 2.5$ million cancer patients diagnosed with one of the nine cancer types were included in our analysis. Table 1 shows the number of patients included for each type of cancer, as well as the mean age of the patients by deprivation group. On average melanoma patients are diagnosed at the youngest age, whereas bladder cancer patients have the oldest age at diagnosis. Age at diagnosis varies slightly by deprivation group for all the cancer types. There was notable variation in the number of patients diagnosed in each deprivation group for melanoma, prostate, breast and lung cancers.

Figure 1 shows the loss in expectation of life and the proportion of life lost for the least- and the most-deprived groups across age at diagnosis for different cancer types in females. The life expectancy of the general population, which is free of cancer, is given in the dashed line in Figure 1. Lung and stomach cancers have the highest loss in all deprivation groups. Melanoma and breast cancer have comparatively much lower loss in expectation of life. Estimates for loss in expectation of life vary widely by age at diagnosis for all cancers except for melanoma and breast cancer. For example, those who were diagnosed at the age of 50 with lung cancer lose nearly 30 years of remaining life, whereas patients above 80 years of age lose $<10$ years. The main cause of death for younger patients is their cancer but death due to other causes becomes more likely as age increases. There is less variation by age for the proportion of life lost, but the variation between the cancer types is similar. For example, females with lung cancer lose $\sim 87 \%$ of their lives for all ages at diagnoses. Results for males were similar and are shown in the Supplementary Figure. Table 2 shows the average loss in expectation of life and the average proportion of life lost, by standardising to the age distribution within each cancer type, deprivation group and sex in 2013. Women lose more years than men, except for melanoma. The highest average loss in expectation of life is for female lung cancer patients at 14.4 to 13.8 years for the least and most deprived, respectively. High values are also observed for males with lung cancer, stomach cancer for both males and females and patients with ovarian cancer. The lowest loss in expectation of life was for females with melanoma; the average loss was 2.9 and 3.1 for the least and most deprived, respectively. Low averages are also observed for prostate and breast cancers. For most of the cancers the loss in expectation of life increases from the least- to the most-deprived groups. A decreasing trend across deprivation groups is observed for prostate, lung, stomach and ovarian cancers.

For some cancer types the decreasing trend in loss in expectation of life across deprivation groups is reversed when considering the proportional scale (e.g., stomach cancer, lung cancer and males with bladder cancer). For example, females with lung cancer lose 14.4 and 13.8 years on average for the least and most deprived, respectively. The equivalent average percentages of life lost are $86.1 \%$ and $87.3 \%$, respectively. This is because mortality due to other causes in the more-deprived group is higher. A decreasing trend from least to most deprived in proportion of life lost was also found for ovarian cancer. On the proportional scale, the highest loss is for males with lung cancer and varies from 87.6 to $88.1 \%$ of expected remaining life lost. The lowest loss is for females with melanoma and varies from 11.7 to $14.3 \%$ across deprivation groups.

The average loss in expectation of life estimates were similar for ovarian cancer and stomach cancer for female patients, ranging between 10.6 and 11.4 years. However, on the proportion of life lost scale the estimates differ due to the higher average age at diagnosis for stomach cancer. For stomach cancer, the proportion of life lost remains above $77 \%$ for all deprivation groups while for ovarian cancer the highest estimate is that of the least deprived at $\sim 60 \%$.

Figures 2 and 3 and Table 3 show the number of patients diagnosed, the estimated total number of life years lost and the mean years lost by sex, deprivation group and cancer type in 2013. Lung cancer results in the largest total life years lost, with the number of years lost in 2013 diagnoses above 30000 years for all deprivation groups and both genders. The total life years lost estimates are influenced by both the number of patients diagnosed and the average years of life lost. For example, even though breast cancer results in few years of life lost on average, because there are many women diagnosed with the cancer, breast cancer has the second largest total life years lost. Prostate cancer has also low average years of life lost but it has large total years lost due to its higher incidence. Melanoma and bladder cancer have the lowest total life years lost. Males lose more years in total in comparison with females for all the cancers considered.

\section{DISCUSSION}

We have estimated the impact of cancer diagnosis by socioeconomic group using absolute and proportional measures of loss in expectation of life for a range of cancer types in England. Our results showed that lung and stomach cancers have the highest loss in expectation of life, whereas melanoma, prostate and breast cancers have the lowest loss on average. A similar pattern was found for the proportion of life lost due to cancer. For some cancers (e.g., lung and stomach cancers) we observed a decreasing effect on loss in expectation of life across deprivation groups, but the trend was reversed for the proportion of life lost. For lung cancer the loss corresponds to nearly all of patients' lives as the proportion of life lost is higher than $85 \%$ for all groups. As the least-deprived patients in the general population have a higher life expectancy to begin with they have more years to lose. Thus, loss in 

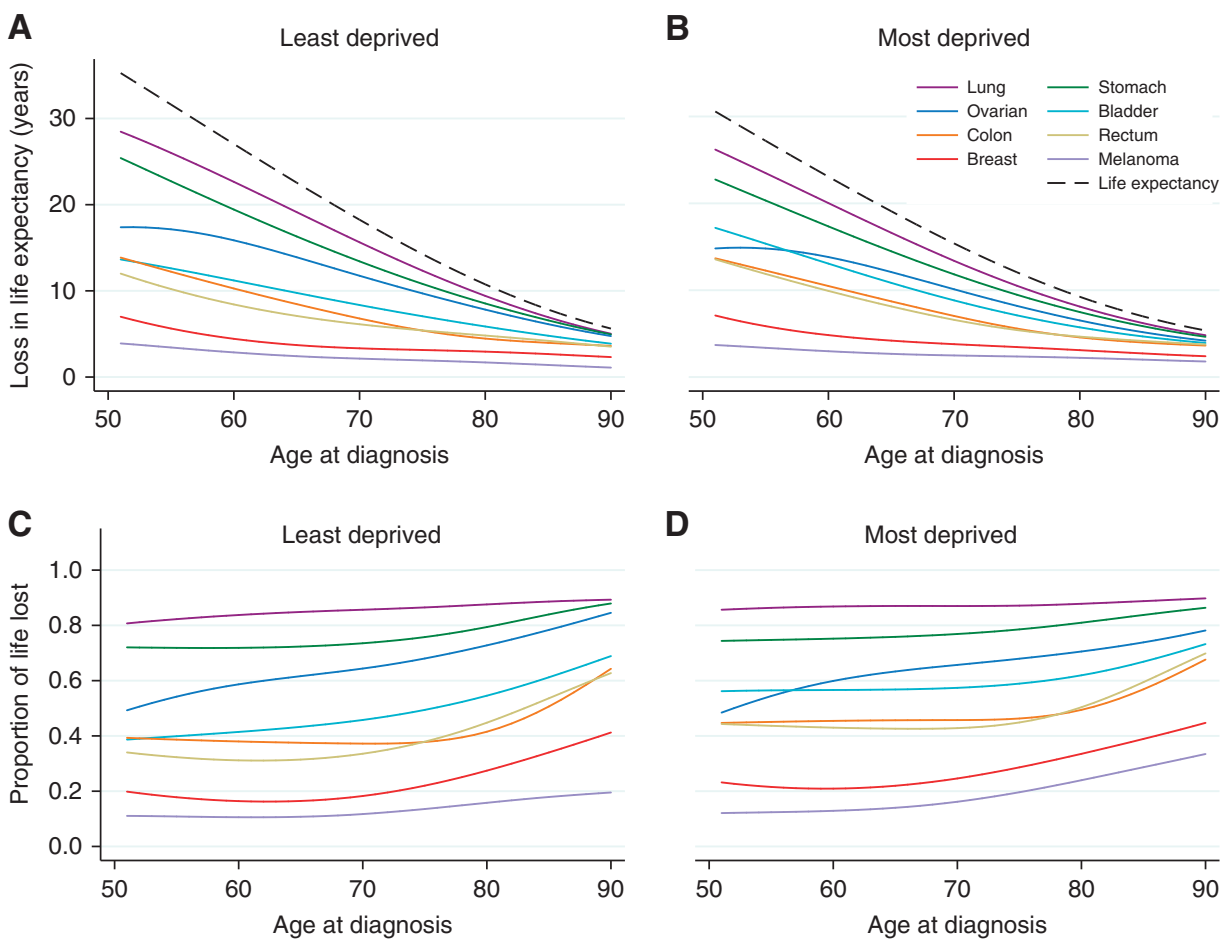

Figure 1. Estimates from a period analysis 2007-2013 (England) for female cancer types. (A) Average loss in expectation of life in years for the least deprived, (B) average loss in expectation of life in years for the most deprived, (C) proportion of life lost for the least deprived and (D) proportion of life lost for the most deprived. Dashed lines in plots A and B show the life expectancy in the general population.

Table 2. Average loss in expectation of life and proportion of life lost for each deprivation group and various cancer types by sex in England

Average loss in life expectancy (years)

Average percentage of life lost (\%)

\begin{tabular}{|c|c|c|c|c|c|c|c|c|c|c|}
\hline Cancer type & Least deprived & 2 & 3 & 4 & Most deprived & Least deprived & 2 & 3 & 4 & Most deprived \\
\hline \multicolumn{11}{|l|}{ Lung } \\
\hline Males & 12.84 & 12.31 & 12.29 & 11.89 & 11.81 & 87.55 & 87.96 & 88.19 & 88.20 & 88.12 \\
\hline Females & 14.42 & 14.17 & 13.82 & 13.78 & 13.82 & 86.07 & 86.75 & 86.75 & 87.03 & 87.26 \\
\hline \multicolumn{11}{|l|}{ Stomach } \\
\hline Males & 11.60 & 10.51 & 10.99 & 10.40 & 10.52 & 78.27 & 78.32 & 78.58 & 79.29 & 79.53 \\
\hline Females & 12.63 & 12.59 & 11.75 & 11.44 & 11.84 & 77.07 & 78.98 & 79.23 & 78.17 & 79.00 \\
\hline \multicolumn{11}{|l|}{ Ovarian } \\
\hline Females & 12.37 & 11.91 & 11.51 & 11.15 & 10.62 & 60.32 & 58.79 & 59.23 & 57.17 & 54.15 \\
\hline \multicolumn{11}{|l|}{ Bladder } \\
\hline Males & 6.04 & 5.44 & 5.58 & 5.58 & 5.61 & 45.42 & 44.30 & 45.69 & 47.09 & 48.26 \\
\hline Females & 7.49 & 7.35 & 7.61 & 7.73 & 8.11 & 51.17 & 53.35 & 54.19 & 58.68 & 60.89 \\
\hline \multicolumn{11}{|l|}{ Colon } \\
\hline Males & 6.67 & 6.37 & 6.34 & 6.34 & 6.84 & 43.21 & 43.38 & 44.17 & 45.17 & 48.18 \\
\hline Females & 7.15 & 6.67 & 7.02 & 7.10 & 7.73 & 41.71 & 42.40 & 43.95 & 44.94 & 48.91 \\
\hline \multicolumn{11}{|l|}{ Rectum } \\
\hline Males & 6.97 & 6.84 & 6.86 & 6.79 & 7.26 & 40.55 & 41.88 & 43.24 & 45.16 & 47.77 \\
\hline Females & 7.18 & 6.88 & 7.25 & 7.19 & 7.96 & 38.95 & 39.01 & 43.58 & 43.54 & 47.61 \\
\hline \multicolumn{11}{|l|}{ Breast } \\
\hline Females & 5.39 & 5.28 & 5.30 & 5.60 & 6.01 & 21.54 & 22.35 & 22.84 & 24.61 & 26.82 \\
\hline \multicolumn{11}{|l|}{ Melanoma } \\
\hline Males & 3.79 & 3.79 & 3.88 & 3.97 & 4.42 & 19.66 & 20.14 & 21.36 & 21.28 & 23.48 \\
\hline Females & 2.85 & 2.78 & 2.78 & 3.15 & 3.06 & 11.73 & 12.47 & 12.37 & 14.30 & 14.05 \\
\hline \multicolumn{11}{|l|}{ Prostate } \\
\hline Males & 3.04 & 2.88 & 2.81 & 2.58 & 2.39 & 21.12 & 21.05 & 21.50 & 20.99 & 20.07 \\
\hline
\end{tabular}



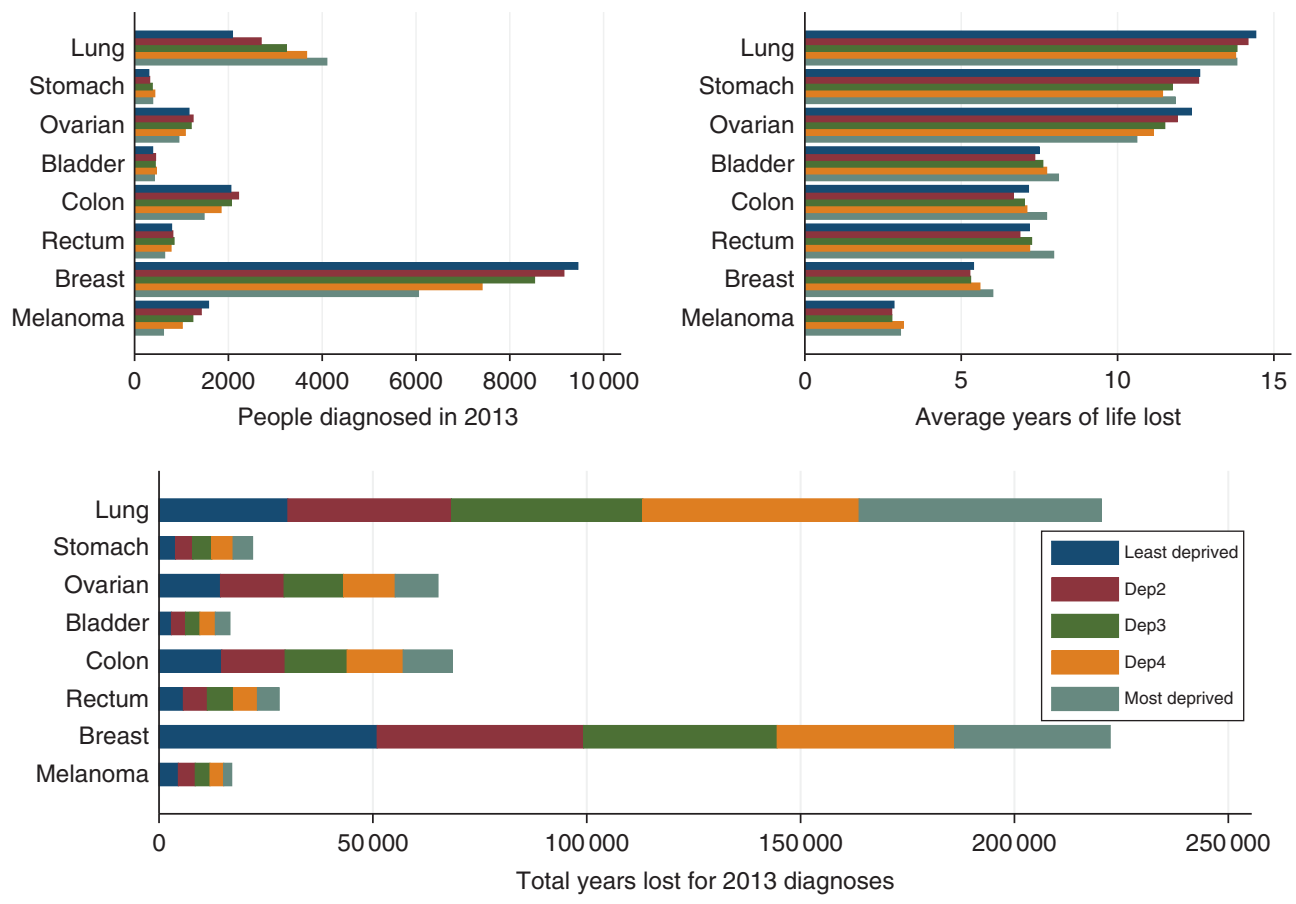

Figure 2. Total years lost in England due to cancer diagnosis in 2013 for females (bottom plot) as a product of the number of patients diagnosed in 2013 (top left plot) and average loss in expectation of life (top right plot) by cancer type and deprivation group. Estimates were obtained from a period analysis 2007-2013.
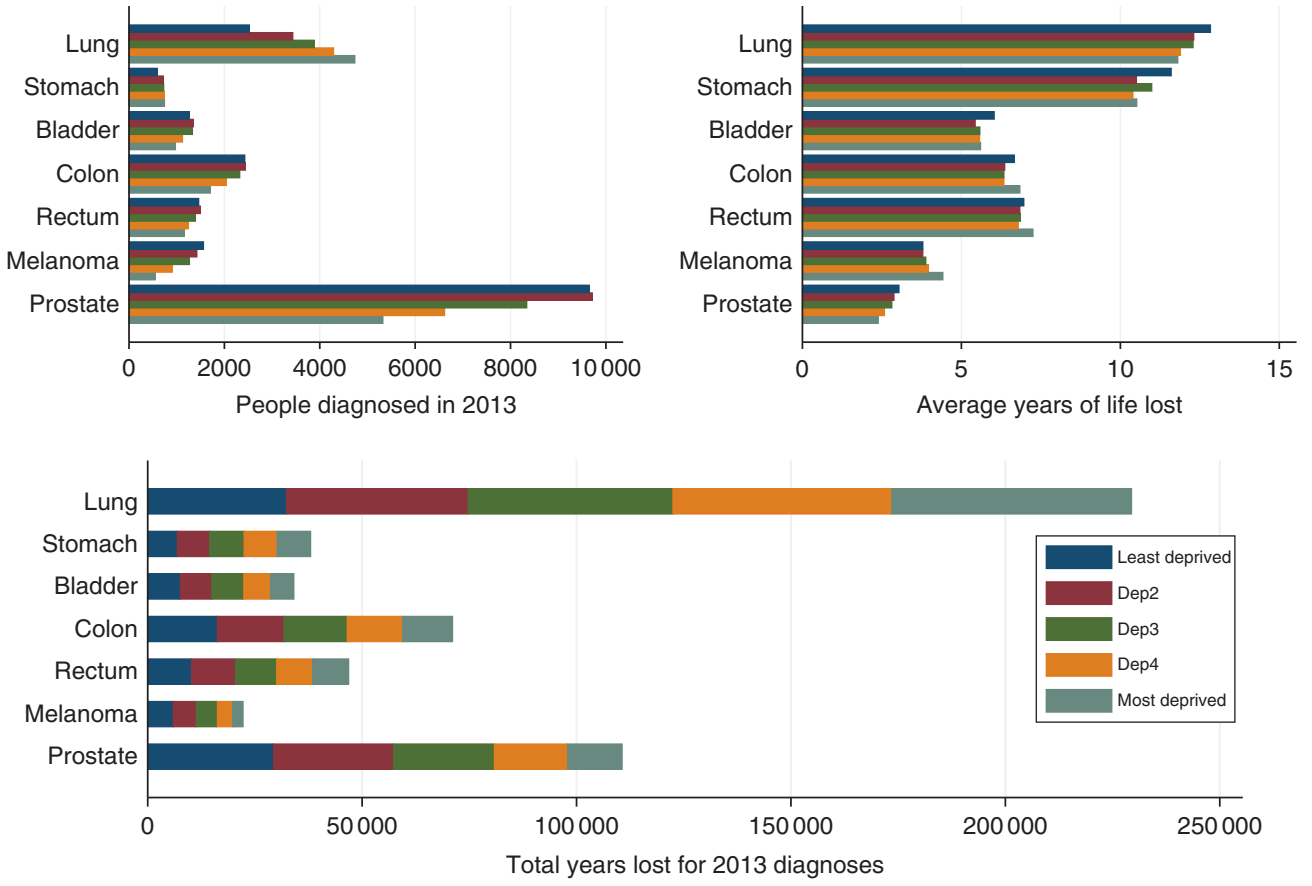

Figure 3. Total years lost in England due to cancer diagnosis in 2013 for males (bottom plot) as a product of the number of patients diagnosed in 2013 (top left plot) and average loss in expectation of life (top right plot) by cancer type and deprivation group. Estimates were obtained from a period analysis 2007-2013.

expectation of life due to cancer will be higher in the least-deprived group. The reversed trend in proportion of life lost is the result of different background mortalities between the deprivation groups. For ovarian cancer, the proportion of life lost remains decreasing with increasing deprivation. This could be partially explained by small differences in cancer-related survival (similar relative survival) and larger different differences in the expected background survival of the general population across deprivation groups. Moreover, the most-deprived group has a younger population in comparison to the least-deprived group. Lung cancer results in the largest total life years lost followed by breast cancer even though it affects only females and not the whole population. Bladder and melanoma cancers result in the lowest total life years lost.

Our results are consistent with previous studies that suggest that survival after a cancer diagnosis in England is markedly different across socio-economic groups with the most deprived usually having lower survival (Coleman et al, 2004; Rachet et al, 2008), 
Table 3. Total life years lost due to cancer diagnosis in 2013 in England by cancer type, deprivation group and sex

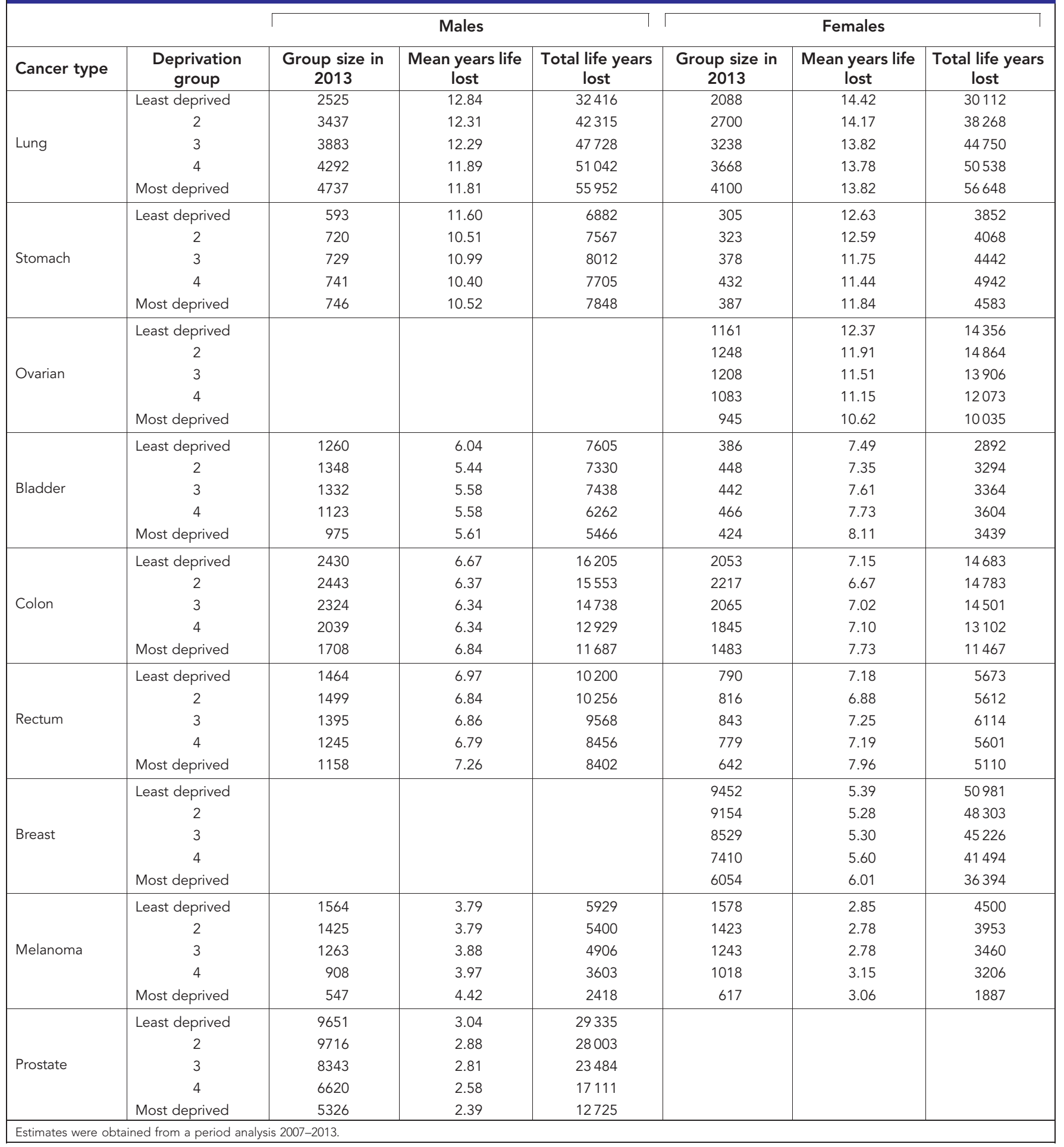

even when adjusting for differences in background survival. We, however, report these differences using a metric that allows easier communication of the impact of cancer on life expectancy by taking a view across the entire lifetime of individuals diagnosed with cancer. Caution is needed when trying to interpret our results in terms of how well the health-care system works for cancer in England. In the general population, which is free of the cancer of interest, the least-deprived group will have a higher life expectancy meaning more life years to lose to begin with. This might result in higher loss in expectation of life for the most affluent. An evaluation of the 2000 NHS Cancer Plan (Department of Health,
2000; Rachet et al, 2010), which aimed to improve survival and reduce inequalities, showed that even though survival after cancer diagnosis has improved in recent years, disparities in cancer outcomes between the least- and the most-deprived groups continue to persist. Similar inequalities in survival have also been reported in other countries in Europe or elsewhere (Dalton et al, 2008; Siemerink et al, 2011; Singh et al, 2011). Even though the tumour biology, patients' characteristics, such as comorbidity, health-seeking behaviours and psychosocial factors, and screening could explain part of the observed differences, the underlying factors for the gap among deprivation groups remain controversial 
(Kaffashian et al, 2003; Lyratzopoulos et al, 2003; Morris et al, 2015). Stage at diagnosis and differences in treatment have been considered to be key factors for differences in survival (Woods et al, 2006; Rutherford et al, 2013). Even though it is anticipated that the estimates in our analysis will vary significantly by stage at diagnosis, no conclusions can be made for the actual variation as information on stage is not included in the analysis. Moreover, like all survival measures, loss in expectation of life can potentially be influenced by screening. However, it is still a useful summary to estimate life expectancy at the population level, including all individuals diagnosed through screening or symptomatically. We consider the differences due to screening to be negligible. The explanations for socio-economic differences is not well documented and further research is required to improve understanding of the factors that drive differences in survival.

To estimate loss in expectation of life using our approach, extrapolation of relative survival is necessary. This has previously been shown to be robust (Andersson et al, 2013), but we performed a sensitivity analysis with regard to some of the assumptions made when extrapolating to ensure that the estimates are not overly influenced (see Supplementary Material for details). Period analysis was also used so that the most recently available information on cancer patient survival is used. In this way, patients with the longest follow-up are used for the long-term predictions and newly diagnosed patients are used for the short-term survival meaning that long extrapolation is not required (Brenner and Hakulinen, 2006; Brenner and Hakulinen, 2009). The use of period analysis strengthens the analysis as we can get reliable estimates of longterm survival.

Loss in expectation of life, both on the absolute and proportional scale, as well as the total life years lost measures are not directly comparable across deprivation groups as the age distribution may vary across groups. The main interest of the study was to calculate estimates that were relevant to the English population and its characteristics (such as age at diagnosis) rather than an international standard population (Corazziari et al, 2004) that would allow a more fair comparison but has different characteristics. This enables the identification the least- and mostaffected groups in England. To ensure that average estimates are not influenced by imbalances in our population (particularly by age) we also conducted an external standardisation additionally to the internal standardisation. External standardisation, for the average estimates of loss in expectation of life and proportion of life lost in Table 2, was performed by either calculating weights from the patients diagnosed in year 2013 in all deprivation groups or by using the International Cancer Survival Standard weights. Different ways of averaging did not have an important influence on the comparisons between deprivation groups as there were not large difference in age between the deprivation groups.

Loss in expectation of life is a measure that is highly dependent on age. Younger patients have more years to lose than older patients and this heavily affects the loss in expectation of life measure. The proportion of life lost is a more stable measure across age and can be used to report the impact of cancer on patients' life expectancy. However, it is not a perfect measure for performing comparisons across groups with differing background survival and it is still influenced by the expected life remaining; if two groups have the same relative survival, but different expected survival, the proportional measure will result in different estimates. However, it does provide a 'real world' measure of survival. Both loss in expectation of life and proportion of life can improve communication and provide further understanding on how inequalities, such as socio-demographic differences, affect cancer patient survival across their whole lifetime and they can be a measure of great interest for public health, clinicians and potentially patients. They can also be used to quantify the disease burden for society, drive policy interventions and motivate awareness campaigns for the most-affected subgroups to eliminate inequalities whenever this is possible. The measures are easy to interpret and existing software can be used for their estimation. Together with relative survival measures, which are more appropriate when the interest is in comparisons across groups whilst removing different expected mortality rates, the measures presented here can help us understand different aspects of the cancer of interest. On the one hand, relative survival is useful for making comparisons across time, across different age groups in our population and across different countries. On the other hand, loss in expectation of life provides 'real world' estimates for the actual impact of cancer in the population of interest.

Even though survival after a cancer diagnosis has increased during the last years, the impact of cancer on life expectancy varies across socio-economic groups. The gap between the most and least affluent suggest that further action is required to tackle health inequalities, by ensuring access to screening procedures and optimal health-care services and treatment for the whole population. Further statistical analysis should focus on the underlying determinants of these inequalities. Loss in expectation of life measures and total life years lost are easily understood measures that can be used to improve understanding and explore variation therefore their use is encouraged.

ACKNOWLEDGEMENTS

This work was funded by Cancer Research UK (Grant number C1483/A18262).

\section{CONFLICT OF INTEREST}

The authors declare no conflict of interest.

\section{REFERENCES}

Andersson TML, Dickman PW, Eloranta S, Lambe M, Lambert PC (2013) Estimating the loss in expectation of life due to cancer using flexible parametric survival models. Stat Med 32: 5286-5300.

Andersson TML, Dickman PW, Eloranta S, Sjövall A, Lambe M, Lambert PC (2015) The loss in expectation of life after colon cancer: a populationbased study. BMC Cancer 15(1): 412.

Bower H, Björkholm M, Dickman P, Höglund M, Lambert P, Andersson TM-L (2016) The life expectancy of chronic myeloid leukemia patients is approaching the life expectancy of the general population. J Clin Oncol 34(24): 2851-2857.

Brenner H, Hakulinen T (2006) Period estimates of cancer patient survival are more up-to-date than complete estimates even at comparable levels of precision. J Clin Epidemiol 59(6): 570-575.

Brenner H, Hakulinen T (2007) Maximizing the benefits of model-based period analysis of cancer patient survival. Cancer Epidemiol Biomarkers Prev 16(8): 1675-1681.

Brenner H, Hakulinen T (2009) Up-to-date cancer survival: period analysis and beyond. Int J Cancer 124(6): 1384-1390.

Brenner H, Söderman B, Hakulinen T (2002) Use of period analysis for providing more up-to-date estimates of long-term survival rates: empirical evaluation among 370000 cancer patients in Finland. Int J Epidemiol 31(2): 456-462.

Coleman MP (2014) Cancer survival: global surveillance will stimulate health policy and improve equity. Lancet 383(9916): 564-573.

Coleman MP, Rachet B, Woods LM, Mitry E, Riga M, Cooper N, Quinn MJ, Brenner H, Estève J (2004) Trends and socioeconomic inequalities in cancer survival in England and Wales up to 2001. Br J Cancer 90(7): 1367-1373.

Corazziari I, Quinn M, Capocaccia R (2004) Standard cancer patient population for age standardising survival ratios. Eur J Cancer 40(15): 2307-2316. 
Dalton SO, Schüz J, Engholm G, Johansen C, Kjær SK, Steding-Jessen M, Storm HH, Olsen JH (2008) Social inequality in incidence of and survival from cancer in a population-based study in Denmark, 1994-2003: Summary of findings. Eur J Cancer 44(14): 2074-2085.

Department for Communities and Local Government (2011) The English Indices of Deprivation 2010. Available at: http:// www.communities.gov.uk/documents/statistics/pdf/1871208.pdf.

Department of Health (2000) The NHS Cancer Plan. Department of Health: London, UK.

Department of Health (2011) Improving Outcomes: A Strategy for Cancer. Department of Health: London, UK.

Ito Y, Nakaya T, Nakayama T, Miyashiro I, Ioka A, Tsukuma H, Rachet B (2014) Socioeconomic inequalities in cancer survival: a population-based study of adult patients diagnosed in Osaka, Japan, during the period 1993-2004. Acta Oncol 53: 1423-1433.

Kaffashian F, Godward S, Davies T, Solomon L, McCann J, Duffy SW (2003) Socioeconomic effects on breast cancer survival: proportion attributable to stage and morphology. Br J Cancer 89: 1693-1696.

Lyratzopoulos G, West CR, Williams EMI (2003) Socioeconomic variation in colon cancer tumour factors associated with poorer prognosis. Br J Cancer 89: 828-830.

Morris M, Woods LM, Rachet B (2016) What might explain deprivationspecific differences in the excess hazard of breast cancer death amongst screen-detected women? Analysis of patients diagnosed in the west midlands region of England from 1989 to 2011. Oncotarget 7: 49939-49947.

Morris M, Woods LM, Rogers N, O'Sullivan E, Kearins O, Rachet B (2015) Ethnicity, deprivation and screening: survival from breast cancer among screening-eligible women in the west midlands diagnosed from 1989 to 2011. Br J Cancer 113: 548-555.

Neighbourhood Renewal Unit (2004) The English indices of Deprivation 2004 (revised). Office of the Deputy Prime Minister: London, UK.

Nelson CP, Lambert PC, Squire IB, Jones DR (2007) Flexible parametric models for relative survival, with application in coronary heart disease. Stat Med 26(30): 5486-5498.

Rachet B, Ellis L, Maringe C, Chu T, Nur U, Quaresma M, Shah A, Walters S, Woods L, Forman D, Coleman MP (2010) Socioeconomic inequalities in cancer survival in England after the NHS cancer plan. Br J Cancer 103: 446-453.

Rachet B, Maringe C, Nur U, Quaresma M, Shah A, Woods LM, Ellis L, Walters S, Forman D, Steward J, Coleman MP (2009) Population-based cancer survival trends in England and Wales up to 2007: an assessment of the NHS cancer plan for England. Lancet Oncol 10: 351-369.

Rachet B, Woods LM, Mitry E, Riga M, Cooper N, Quinn MJ, Steward J, Brenner H, Estève J, Sullivan R, Coleman MP (2008) Cancer survival in
England and Wales at the end of the 20th century. Br J Cancer 99(Suppl 1): S2-S10.

Royston P (2001) Flexible parametric alternatives to the Cox model, and more. Stata J 1: 1-28.

Royston P, Parmar MKB (2002) Flexible parametric proportional-hazards and proportional-odds models for censored survival data, with application to prognostic modelling and estimation of treatment effects. Stat Med 21(15): 2175-2197.

Rutherford MJ, Andersson TML, Møller H, Lambert PC (2015) Understanding the impact of socioeconomic differences in breast cancer survival in England and Wales: avoidable deaths and potential gain in expectation of life. Cancer Epidemiol 39: 118-125.

Rutherford MJ, Hinchliffe SR, Abel GA, Lyratzopoulos G, Lambert PC, Greenberg DC (2013) How much of the deprivation gap in cancer survival can be explained by variation in stage at diagnosis: An example from breast cancer in the East of England. Int J Cancer 133(9): 2192-2200.

Siemerink EJM, Hospers GAP, Mulder NH, Siesling S, van der Aa MA. (2011) Disparities in survival of stomach cancer among different socioeconomic groups in north-east Netherlands. Cancer Epidemiol 35: 413-416.

Singh GK, Williams SD, Siahpush M, Mulhollen A (2011) Socioeconomic, rural-urban, and racial inequalities in us cancer mortality: part I-all cancers and lung cancer and part II-colorectal, prostate, breast, and cervical cancers. J Cancer Epidemiol 2011: 107497.

Spika D, Rachet B, Bannon F, Woods L, Maringe C, Bonaventure A, Coleman M, Allemani C. Life tables for the concord-2 study. Available at http:// csg.lshtm.ac.uk/life-tables (accessed on October 2016).

Sprague BL, Trentham-Dietz A, Gangnon RE, Ramchandani R, Hampton JM, Robert SA, Remington PL, Newcomb PA (2011) Socioeconomic status and survival after an invasive breast cancer diagnosis. Cancer 117: $1542-1551$

StataCorp (2015) Stata Statistical Software: Release 14. StataCorp LP: College Station, TX, USA.

Van der Heyden JHA, Schaap MM, Kunst AE, Esnaola S, Borrell C, Cox B, Leinsalu M, Stirbu I, Kalediene R, Deboosere P, Mackenbach JP, Van Oyen H (2009) Socioeconomic inequalities in lung cancer mortality in 16 European populations. Lung Cancer 63: 322-330.

Woods LM, Rachet B, Coleman MP (2006) Origins of socio-economic inequalities in cancer survival: a review. Ann Oncol 17: 5-19.

(c) (i) This work is licensed under the Creative Commons Attribution 4.0 International License. To view a copy of this license, visit http://creativecommons.org/licenses/by/4.0/

(C) The Author(s) named above 2017

Supplementary Information accompanies this paper on British Journal of Cancer website (http://www.nature.com/bjc) 